\title{
BAHASA PEDAGANG IKAN DI PASAR PANORAMA BENGKULU (KAJIAN SOSIOLINGUISTIK)
}

\author{
Yetri Fitriani ${ }^{1,}$ Ngudining Rahayu $^{2}$, dan Catur Wulandari ${ }^{3}$ \\ ${ }^{1,2,3}$ Program Studi Pendidikan Bahasa dan Sastra Indonesia \\ Jurusan Pendidikan Bahasa dan Seni \\ FKIP Universitas Bengkulu \\ Yetri pitriani@yahoo.co.id
}

\begin{abstract}
Abstrak
Tujuan penelitian ini adalah mendeskripsikan (1) variasi bahasa yang dilihat dari segi penutur yaitu idiolek, asal daerah, jenis kelamin dan usia. (2) mendeskripsikan fungsi bahasa yang digunakan pedagang ikan di Pasar Panorama Bengkulu. Penelitian ini menggunakan metode deskriptif kualitatif, dengan teknik pengumpulan data menggunakan teknik rekam, dan teknik catatan lapangan. Teknik analisis data dalam penelitian ini meliputi transkripsi data, identifikasi data, klasifikasi data, kode data, interpretasi data, dan menyimpulkan. Hasil penelitian ini menunjukkan bahwa (1) bahasa pedagang ikan di pasar Panorama Bengkulu yang dilihat dari segi penutur terdapat idiolek penutur yang menggunakan pilihan kata yang dan bunda sebagai kata sapaan untuk pembeli yang menunjukkan cirri kekhasan seorang penutur, dan sosiolek penutur yaitu asal daerah yang mempengaruhi terjadinya kevariasian bahasa penutur yang menggunakan bahasa Melayu Bengkulu, bahasa Serawai daerah Seluma dan Bengkulu Selatan, bahasa Lintang Empat Lawang, dan bahasa Jawa, serta pilihan kata, kalimat dan kata sapaan yang digunakan penutur menunjukkan jenis kelamin yaitu ujaran pedagang yang berjenis kelamin laki-laki cenderung singkat namun jelas, dalam ujarannya tidak banyak basa-basi seperti pedagang ikan yang berjenis kelamin perempuan yang menggunakan ujaran cenderung panjang dan banyak basa-basi untuk mempengaruhi pembeli. Dan dari segi usia terdapat pedagang yang berusia 30 dan 40 tahun yang menggunakan kata seperlunya dan lansung ketujuan pembicaraannya seperti "ikanya mbak" dan "tigo limo be, jadi?". (2) Terdapat beberapa fungsi bahasa pedagang terdiri dari fungsi personal yaitu ungkapan perasaan atau pungagasan yang ada dipikiran penuturnya. Fungsi regulatori, interaksional, instrumental, danheuristik, dalam berkomunikasi dengan pembeli ketika proses jual beli di pasar Panorama Bengkulu.
\end{abstract}

\section{Kata kunci: Variasi, fungsi, bahasa, pedagan}

\begin{abstract}
The purpose of this study is to describe the first variantions of language seen in terms of speakers of idiolek, regional origin, gender, and age. The second describes the function of the language used by fish trades in Panorama Bengkulu market. The research uses qualitative descriptive method, with data collection technique, and field note technique. Data analysis techniques in this study include data transcription, data classification, data code, data interpretation, and concluding. The results of this study indicate that the first language of fish traders in Panorama Bengkulu market seen in terms of speakers there idiolek speakers who use the choice of the word "yang" and "mother" as a greeting to buyers who show the characteristic of a speaker, and sosiolek speakers that are the origin of the region that influences the occurrence of variantion language speakers who use Bengkulu
\end{abstract}


Malay, Serawai language in Seluma area, and Serawai language in Bengkulu Selatan area, Lintang language in Empat Lawang area, and the language of Jawa, and the choice of words sentesces, and greetings used speakers show the gender le the male merchant's expression tends to be brief but clear, in his speech is not a lot of preamble like fish traders who are sex women using speech tend to longand a lot of pleasantries to influence buyers. In terms of age there are traders who are aged 30 and 40 years who use the word necessary and directly to the goal of his conversation sech as "fish mbak" and "thirty five thousand only, want?". The second there is the language function of the composer which consists of personal functions, interactional functions, instrumental functions, and heuristic functions. In communicating with buyers when buying and selling fish in the Panorama Bengkulu market.

\section{Keyword: variations, functions, languages, merchants}

\section{PENDAHULUAN}

Bahasa adalah alat berinteraksi atau alat untuk berkomunikasi dan menyampaikan pikiran, gagasan, konsep, atau juga perasaan, yang hanya dimiliki oleh manusia (Chaer \& Agustina, 2010:14). Bahasa memiliki peran yang sangat penting dalam kehidupan manusia, untuk menjalankan kehidupan bersosial.

Masyarakat mengguanakan media bahasa sebagai sarana atau alat berkomunikasi yang dapat dipahami oleh lawan tuturnya, yang bertujuan untuk mendapatkan ataupun menyampaikan informasi yang dibutuhkannya. Penggunaan bahasa dikatakan mampu menyampaikan informasi dengan baik apabila terdapat kesesuaian antara bahasa penutur dan lawan tutur serta terdapat kesesuaian dengan peristiwa tutur yang berlangsung. . Peristiwa tutur adalah peristiwa terjadinya atau berlangsungnya interaksi linguistik dalam satu bentuk ujaran atau lebih yang melibatkan dua pihak, yaitu penutur dan lawan tutur, dengan satu pokok tuturan, di dalam waktu, tempat, dan situasi tertentu (Chaer \& Agustina, 2010:47).

Masyarakat tutur yang heterogen dapat menimbulkan berbagai penggunaan variasi bahasa ketika berinteraksi dengan lawan tuturnya. Variasi bahasa terjadi karena kegiatan interaksi sosial yang mereka lakukan sangat beragam. Setiap kegiatan dapat menyebabkan terjadinya variasi bahasa. Penggunaan variasi semakin bertambah jika bahasa tersebut digunakan oleh penutur yang sangat banyak, serta dalam wilayah yang sangat luas.

Terjadinya penggunaan variasi bahasa dipengaruhi oleh latar belakang penutur maupun situasi saat tuturan berlangsung. Hal ini sejalan dengan Chaer \& Agustina (2010) yang menegaskan bahwa variasi bahasa dapat dilihat dari segi penutur yaitu membicarakan siapa yang menggunakan bahasa tersebut, di mana tinggalnya, bagaimana kedudukan sosialnya di dalam masyarakat, apa jenis kelaminnya, dan kapan bahasa itu digunakan. Serta berdasarkan penggunaannya untuk apa bahasa itu digunakan, di bidang apa dan bagaimana bahasa itu digunakan.

Pasar Panorama Kota Bengkulu merupakan salah satu pasar terbesar di, yang menyediakan segala kebutuhan masyarakat mulai dari sembako, alat-alat rumah tangga, sayur-mayur, ikan, ayam dan lain sebagainya yang dijual para pedagang. Pedagang dan pembeli di pasar ini tidak hanya berasal dari Kota Bengkulu saja melainkan juga terdapat dari luar Kota Bengkulu seperti pedagang dan pembeli dari Kabupaten Seluma dengan suku 
Serawai, Kabupaten Kepahiang dengan Suku Rejang, bahkan ada yang dari luar Provinsi Bengkulu seperti Suku Batak dan Jawa.

Pasar Panorama Kota Bengkulu ini memiliki penutur dengan latar belakang dan status sosial yang berbeda-beda. Dalam melakukan proses jual beli di pasar, pedagang dan pembeli (penutur dan petutur) menggunakan bahasa sebagai alat komunikasi untuk menyampaikan pikiran maupun gagasannya dalam jual beli suatu barang yang dikehendakinya. Sehingga dalam komunikasi antara pedagang dan pembeli dapat mengakibatkan terjadinya penggunaan variasi bahasa dan fungsi bahasa ketika proses jual beli tersebut.

Teori yang digunakan dalam penelitian ini adalah teori Sosiolinguistik, variasi bahasa, peristiwa tutur dan fungsi bahasa.

\section{a. Sosiolinguistik}

Sosiolinguistik merupakan ilmu antardisipliner antara sosiologi dan linguistik, dua bidang ilmu empiris yang mempunyai kaitan sangat erat, maka untuk memahami apa sosiolinguistik itu perlu dibicarakan terlebih dahulu apa maksud dengan sosiologi dan linguistik itu. Sosiologi adalah kajian objektif dan ilmiah mengenai manusia di dalam masyarakat, dan mengenai lembaga-lembaga, dan proses sosial yang ada di dalam masyarakat. Linguistik adalah bidang ilmu yang mmpelajari bahasa, atau bidang ilmu yang mengambil bahasa sebagai objek kajiannya (Rokhman, 2013).

Padmadewi, Merlyna, \& Saputra (2014:1) mengatakan bahwa sosiolinguistik adalah ilmu yang mempelajari tentang bahasa dan orang-orang yang memakai bahasa itu. Selain itu Kridalaksana (dalam Chaer \& Agustina 2010) mendefinisikan sosiolinguistik sebagai cabang linguistik yang berusaha menjelaskan ciri-ciri variasi bahasa dan menetapkan korelasi ciri-ciri variasi tersebut dengan ciri-ciri sosial kemasyarakatan. Dengan demikian, dapat dikatakan bahwa sosiolinguistik adalah bidang ilmu antardisiplin yang mempelajari bahasa dalam kaitannya dengan penggunaan bahasa itu di dalam masyarakat.

\section{b. Variasi Bahasa}

Variasi bahasa adalah bentuk-bentuk bagian atau varian dalam bahasa yang masing-masing memiliki pola yang menyerupai pola umum bahasa induknya, Poedjosoedarmo (dalam Suwito, 1982:20 yang dikutip oleh Aslinda \& Syafyahya, 2007:17). Selain itu Padmadewi, Merlyna, \& Saputra (2014:7) mengatakan bahwa variasi bahasa adalah jenis atau ragam bahasa yang pemakaiannya disesuaikan dengan fungsi dan situasinya

Chaer \& Agustina (2010:61) membagi variasi bahasa berdasarkan variasi dari segi penutur, variasi dari segi pemakaiannya, variasi dari segi keformalan, dan variasi dari segi sarana.

\section{Variasi dari Segi Penutur}

\section{(a) Idiolek}

Idiolek adalah variasi bahasa yang bersifat perseorangan atau individu (Chaer \& Agustina, 2010:62). Dengan demikian dapat dikatakan bahwa idiolek adalah variasi yang dimiliki setiap individu yang memiliki ciri atau kekhasan tersendiri yang menandainya.

\section{(b) Dialek}

Dialek adalah variasi bahasa dari sekelompok penutur yang jumlahnya relatif, yang berada pada suatu tempat, wilayah atau area tertentu (Chaer \& Agustina, 2010:63).

\section{(c) Kronolek}

Chaer dan Agustina (2010:64) menjelaskan bahwa kronolek atau dialek temporal adalah variasi bahasa yang digunakan oleh kelompok sosial pada masa tertentu. 


\section{(d) Sosiolek}

Chaer \& Agustina (2010:64) mengatakan bahwa Sosiolek atau dialek sosial adalah variasi bahasa yang berkenaan dengan status, golongan, dan kelas sosial penuturnya.

(1) Variasi bahasa berdasarkan usia

(2) Variasi bahasa berdasarkan pendidikan

(3) Variasi bahasa berdasarkan seks

(4) Variasi bahasa berdasarkan pekerjaan

(5) Variasi bahasa berdasarkan keadaan sosial ekonomi

(6) Variasi bahasa berdasarkan keadaan sosial ekonomi

\section{c. Peristiwa Tutur}

Peristiwa tutur adalah terjadinya atau berlangsungnya interaksi linguistik dalam satu bentuk ujaran atau lebih yang melibatkan dua pihak, yaitu penutur dan lawan tutur, dengan satu pokok ujaran, di dalam waktu, tempat, dan situasi tertentu (Chaer \& Agustina, 2010:47). Sejalan dengan itu Dell Hymes 1972 (Nababan, 1984:7) mengatakan bahwa dalam penggunaan bahasa ada delapan unsur yang diperhatikan.

$\begin{aligned} & \mathrm{S}=\text { Setting and scene } \\ & \mathrm{P}=\text { Participants } \\ & \mathrm{E}=\text { Ends : purpose and goal } \\ & \mathrm{A}=\text { Act sequnces } \\ & \mathrm{K}=\text { Key }: \text { tone or spirit of act } \\ & \mathrm{I}=\text { Instrumentalities } \\ & \mathrm{N}=\text { Norms of interaction and } \\ & \mathrm{G}=\text { innterpretation } \\ &\end{aligned}$

\section{d. Fungsi Bahasa}

Sebagai alat komunikasi dalam berinteraksi di dalam bermasyarakat tentu saja bahasa memiliki fungsi untuk menyampaikan informasi kepada lawan tutur. Chaer \& Agustina (2010:15) mengatakan bahwa fungsi-fungsi bahasa dapat dilihat dari sudut penutur, pendengar, topik, kode dan amanat pembicaraan. Hal ini sejalan dengan yang dikemukakan oleh Halliday (dalam Alwasilah, 1985:27) yang membagi fungsi bahasa menjadi beberapa fungsi yaitu : personal, regulatori atau direktif, representasional, interaksional, heuristik, imajinatif.

1) Personal, yaitu bahasa berfungsi untuk menyatakan sikap terhadap yang dituturkan.

2) Regulatori, yaitu mengatur tingkah laku pendengar. Dalam fungsi ini tidak hanya membuat pendengar melakukan sesuatu, bertindak atau berkata, tetapi melakukan kegiatan yang sesuai dengan yang direncanakan si pembicara.

3) Interaksional, yaitu fungsi bahasa sebagai menjalin hubungan, memeliharanya, memperlihatkan perasaan persahabatan atau solidaritas sosial. Ungkapanungkapan dipakai biasanya sudah mempola seperti waktu pamit, waktu berjumpa, membicarakan cuaca, bertanya tentang kesehatan keluarga.

4) Representasional, fungsi Ini mengacu kepada bahasa sebagai alat untuk membicarakan objek/peristiwa dalam lingkungan sekeliling atau di dalam kebudayaan pada umumnya.

5) Imajinatif, bahasa bisa kita pakai untuk mengungkapkan pikiran atau gagasan baik sesunggunya atau tidak, perasaan dan khayalan.

6) Heuristik, berfungsi untuk menyelidiki realitas, yang dapat mengajarkan banyak hal. Dengan fungsi ini sesorang dapat menemukan sesuatu dengan sendirinya dan dapat memecahkan masalah yang dikehendaki penuturnya. 
7) Instrumental, yaitu sebagai alat untuk menggerakkan serta memanipulasi lingkungan atau menyebabkan suatu peristiwa terjadi.

\section{METODE}

Penelitian ini dilakukan di pasar Panorama Kota Bengkulu pada tanggal 13 Februari sampai 13 Maret 2017. Tempat penelitian ini adalah kios-kios pedagang ikan di pasar Panorama Bengkulu. Terdapat 8 kios pedagang ikan. Kios ini terletak di sebelah kanan bagian belakang pasar yang berdekatan dengan kios penjual manisan dan sayur-mayur. Metode yang digunakan dalam penelitian ini adalah metode deskriptif

Dalam penelitian ini yang menjadi instrumen atau alat penelitian adalah peneliti itu sendiri (human instrument), yang berfungsi menetapkan fokus penelitian, menetapkan informan sebagai sumber data, melakukan pengumpulan data, analisis data, menafsirkan data dan sampai menyajikan laporan hasil penelitian (Sugiyono, 2014:222). Selain itu pada penelitian ini menggunakan instrumen penelitianalat perekam dan kartu data.

\section{HASIL DAN PEMBAHASAN}

Hasil

\section{Variasi Bahasa dari Segi Penutur}

a. Idiolek

Idiolek adalah variasi bahasa yang bersifat perseorangan atau individu (Chaer \& Agustina, 2010:62).

Data 1 : PD1/PB2/U78

Pembeli (2) : berapo?

[bərapo]

(berapa?) (7)

Pedagang (1): duo-duo sekilo yang [duo duo səkilo yañ]

(dua puluh dua ribu sekilo yang) (8)

Data 2 : PD1/PB6/U59

Pedagang (1) : yaang cumi yaang, cumi yang, yaang yaang $(59)$
Pembeli (6) : pacak sepuluh ribu yuk? [paca? Səpuluh ribu yu?]

(bisa sepuluh ribu yuk) (60)

Dari kutipan percakapan pedagang 1 dengan beberapa orang pembeli pada data di atas menunjukkan bahwa idiolek pedagang sebagai ciri kekhasannya terdapat pada pilihan kata yang digunakan yaitu kata [yang] sebagai kata sapaan yang ditujukan kepada pembeli seperti pada tuturan (2) [duo-duo sekilo yañ], (8) [yaañ cumi yaañ, cumi yang, yaañ yañ], (83) [wei baru itu yañ..... pagi tadi lah itu yañ...]. Pedagang ini tetap menggunakan kata "yang" meskipun pembeli datang dari kalangan yang berbeda-beda, baik latar belakang, maupun usia.

Pedagang ikan ini bernama Salimin. Dari kutipan percakapan pedagang 1 dengan ke tiga pembelinya dapat disimpulkan bahwa pengunaan kata sapaan [yañ] merupakan suatu kebiasaannya yang menandakan ciri kekhasannya dalam menyapa pembeli, karena saat penelitian berlangsung hanya menemukan pedagang 1 yang menggunakan kata sapaan tersebut.

Pilihan kata yang digunakan penutur yang menandakan ciri kekhasannya juga terdapat pada pedagang 8, seperti pada data berikut : Data 6: PD8/PB1/U169 Pedagang (8): iyo, kalu setengah sepuluh [iyo, kalu sətñah səpuluh] (lya. Kalau setengah kilo sepuluh ribu) (167)

Pembeli (1) : idak kurang lagi yuk [ida? kurañ lagi yu?] (tidak bisa kurang lagi yuk?) (168)

Pedagang (8): idak kurang lagi bunda

[ida? kurañ lagi bunda] (lembut dan jelas, ikan idak ado, baru nyampai, dapat dikit nian [ikan ida? Ado, 
baru ñampai, dapat dikit nian]

(tidak bisa bunda, ikan tidak ada, baru sampai, Cuma dapat sedikit) (169)

Ciri kekhasan pedagang 8 ini terdapat pada pilihan kata sapaan yang digunakan untuk menyapa pembeli yaitu dengan kata [bunda], seperti yang terdapat pada tuturan (169) [ida? kurañ lagi bunda...] yang berarti bahwa ia tidak bisa mengurangi harga ikan tersebut, karena sulitnya mendapatkan ikan dan ia cuma mendapatkan sedikit ikan untuk berjualan. Dengan menggunakan kata sapaan bunda kepada pembeli, pembeli akan merasa nyaman dan akrab sehingga dapat menyebabkan ketertarikan untuk membeli ikan dagangannya.

Pengunaan kata sapaan [bunda] oleh pedagang 1 terjadi bukan hanya menghadapi satu pembeli saja tetapi hampir pada setiap pembeli yang datang untuk membeli dagangannya maupun terhadap orang yang hanya bertanya harga ikannya saja, sehingga dapat dikatakan bahwa penggunaan kata sapaan [bunda] hanya dimiliki oleh pedagang 8 yang menjadikan ciri kekhasannya. Pengucapan kata sapaan oleh pedagang 8 ini terdengar fasih dan tidak ada keraguan ataupun canggung, karena itu sudah menjadi kebiasaan pedagang dalam menyapa pembelinya. Sehingga tak heran jika banyak pembeli yang berdatangan kepadanya.

\section{b. Variasi bahasa berdasarkan asal daerah atau wilayah}

Dari percakapan antara pedagang dan pembeli dalam melakukan kegiatan jual beli ikan di pasar Panorama Bengkulu, terdapat variasi bahasa yang digunakan oleh pedagang ikan berdasarkan asal daerahnya, yaitu : pedagang yang berasal dari kabupaten Seluma dan kabupaten Bengkulu Selatan dengan bahasa Serawai, pedagang dari Kabupaten Empat Lawang dengan bahasa Lintang, Pedagang dari Kota Bengkulu dengan Bahasa Melayu Bengkulu.

\section{Data 8 : PD1/PB1/U3-5}

Pembeli (1) : gaguk ini yuk?

[gagu? Ini yu?]

(ikan gaguk ini yuk?) (2)

Pedagang (1) : kudai, kito kinak i kudai begapo banyak lagi, bayaghlah lapan belas be itu yang, jadilah.

[kudai kito kina? I kudai bəgapo baña? Lagi, bayaplah lapab bəlas be itu yañ, jadilah]

(sebentar, kita lihat dulu ada berapa banyak lagi, bayar saja delapan belas itu yang, tidak apa-apa) (3)

Pembeli (1) : idak limo belas yuk?

Pedagang (1) : yak jangan, daging 25 sekilo dek, itu lah aku enjuak lapan belas bae, daging iluak, daging kental. [ya? jañan, dagiñ 25 səkilo de?, itu lah aku ənjua? Lapan bəlas bae, dagiñ ilua?, dagiñ kəntal] (ya jangan, harga daging ikannya 25 sekilo dek, itu sudah aku kasih delapan belas ribu saja, daging bagus, daging kental) (5)

Pada kutipan percakapan pedagang 1 dengan pembeli pada data di hasil penelitian terlihat bahwa pedagangmenggunakan bahasa Serawai yang ditandai dengan fonem /o/, / $/$, seperti pada kata [bəgapo] , /a/ pada kata [ənjua?], [ilua?], dan /gh/ $\boldsymbol{v}$ pada kata [bayaplah] dapat dilihat pada tuturan (3), apabila diartikan ke dalam bahasa Indonesia berarti "sebentar, kita lihat dulu ada berapa banyak lagi, bayar delapan belas ribu saja yang, tidak apa-apa", dan 
terdapat fonem /ak/ diakhir kata seperti pada tuturan (5) yang di tandai dengan kata [ənjua?], [ilua?], meski lawan tuturnya yaitu pembeli merespon dengan menggunakan bahasa Melayu Bengkulu, pedagang ini tetap menggunakan bahasa Serawai hingga akhir pembicaraan.

Ketika sedang berinteraksi mengenai jual beli ikan dagangannya pedagang 1 sering mencampurkan beberapa bahasa, yaitu bahasa Indonesia, bahasa Melayu Bengkulu dan bahasa Serawai.Disaat mendengar respon pembeli menggunakan bahasa Indonesia pedagang pun ikut menggunakan bahasa Indonesia tetapi hanya beberapa kata saja yang ditandai dengan kata [saja], kemudian dilanjutkan dengan bahasa kesehariannya yaitu bahasa Melayu Bengkulu dan bahasa Serawai seperti pada tuturan (87) bahasa MelayuBengkulu ditandai dengan kata [ida?]dan bahasa Serawai ditandai dengan fonem /gh/ pada kata [nəñay] apabila diartikan ke dalam bahasa Indonesia berarti dengar.

Hal ini terjadi dalam kewajaran karena latar belakang pedagang 1 yang bertempat tinggal di Betungan merupakan seorang perempuan kelahiran Tais Kabupaten Seluma yang memang pada kesehariannya masyarakat Seluma merupakan masyarakat suku Serawai. Masyarakat di sekitar tempat tinggal pedagang 1 mayoritas masyarakat pengguna bahasa Serawai. Sehingga dapat mempengaruhi terjadinya kevariasian bahasa ketika berinteraksi dengan orang lain.

\section{Data 47 : PD3/PB1/U128}

Pedagang (3) : Kerong-kerong, kerong dek, limo belas ajo (sambil memegang ikan dan mengarahkan kepada pembeli)

[keroñ-keroñ de?, kero de?, limo bəlas ajo (kerong kerong, kerong dek, Lima belas saja) (128)

Pembeli (1): semuanya pak? (129)

Pedagang (3) : iya semuanya dek $(130$

Dari kutipan percakapan pada data hasil penelitian terlihat bahwa pedagang 3 menggunakan bahasa Melayu Bengkulu seperti yang terdapat pada tuturan (128) yang ditandai dengan fonem /o/ pada kata [limo]dan [ajo] apabila diartikan ke dalam bahasa Indonesia menjadi [lima] dan [saja].

\section{Data 50 : PD4/PB1/U141}

Pedagang (4): ade nek, endak berape nek?

[ade ne?, ənda? Bərape ne?] (ada nek, mau bera nek?) (141)

Pembeli(1): due ikok bae, pacak nedo? nedo galak nian makan

[due iko? Bae, paca? Nedo.nedo gala? Nian makan] (dua ekor saja, bisa tidak? Tidak nafsu makan) (142)

Pedagang (4): pacak galo, na nek ambik a 6 ribu bae, aku nginjok sikok ao", "ikan buk? Ikan apo tengoklah?" (berbicara kepada pembeli yang lewat [paca? Galo, na ne? ambi? A 6 ribu bae, aku ñinjo? Siko? $\mathrm{aO}]$.

Mendengar respon pembeli yang menggunakan bahasa Lintang Empat Lawang seperti pada tuturan (142) yang menjelaskan bahwa pembeli ingin membeli ikan nila dikarenakan ia tidak bisa mengkonsumsi ikan laut karena suatu hal. Maka pedagang 4 ikut menggunakan bahasa tersebut sampai akhir pembicaraan seperti yang terlihat pada tuturan (143) yang ditandai dengan kata [nginjo?] yang berarti memberi, dan [aO] yang berarti iya, 
dengan penggunaan bahasa yang sama proses jual beli bisa berjalan dengan baik.

Pedagang 4 dapat berkomunikasi dengan lancar karena ia merupakan seorang perempuan kelahiran Tebing Tinggi Kabupaten Empat Lawang provinsi Sumatera Selatan yang kesehariannya menggunakan bahasa tersebut, selain bahasa tersebut merupakan bahasa ibunya pedagang ini bertempat tinggal di Muhajirin yang mayoritas penduduk adalah masyarakat pengguna bahasa Lintang.

\section{Data 53 : PD5/PD2/U147-149}

$\begin{aligned} \text { Pedagang (5) } & \text { akap tadi ngapau } \\ & \text { ndiak jualan? } \\ \text { [akap tadi ñapau ndia? } & \\ \text { Jualan] } & \text { (pagi tadi mengapa tidak } \\ & \text { berjualan) (147) } \\ \text { Pedagang (2) } & \text { Hujan lebat nian, } \\ & \text { malas berangkat, ikan lah } \\ & \text { siap galo, idak nian selero } \\ & \text { jualan dingin } \\ & \text { [hujan lebat nian, malas } \\ & \text { bərañkat, ikan lah siap galo, } \\ & \text { ida? nian səlero jualan diñin] } \\ \text { (hujan deras sekali, malas } & \text { berangkat, padahal ikan } \\ & \text { sudah siap semua, tidak ada } \\ & \text { selera untuk berjualan, } \\ & \text { dingin) (148) }\end{aligned}$

Pedagang (5) : $\quad$ ndiak pulau rami, aku pakai baju ujan

[ndia? Pulau rami, aku pakai baju ujan]

(tidak pula rame, saya mengenakan mantel hujan) (149)

Kutipan Percakapan pada data di atas merupakan bahasa pedagang yang menggunakan bahasa Serawai Bengkulu Selatan seperti yang terdapat pada tuturan (147) yang ditandai dengan akhiran /au/ dan /ak/ seperti pada kata [ñapau], dan [ndia?], dan pada tuturan (149) yang ditandai dengan kata [ndia? Pulau] jika diartikan ke dalam bahasa Indonesia berarti [tidak juga], meskipun lawan tuturnya merespon menggunakan bahasa Melayu Bengkulu pedagang ini tetap menggunakan bahasa Serawai Bengkulu Selatan dalam berkomunikasi dengan lawan tuturnya, hal ini karena latar belakang penutur merupakan seorang perempuan yang berusia 36 tahun kelahiran Masat kabupaten Bengkulu Selatan sehingga penggunaan bahasa ibunya masih sangat kental.

\section{c. Variasi bahasa berdasarkan jenis kelamin}

Data 68 : PD1/PD1/U3

Pembeli (1): kudai, kito kinak i kudai begapo banyak lagi, bayaghlah lapan belas be itu yang, jadilah.

[kudai, kito kina? i kudai bəgapo baña? Lagi, bayaylah lapan bəlas be itu yañ jadilah] (sebentar, kita lihat dulu ada berapa banyak lagi, bayar saja delapan belas itu yang, gak apa-apa) (3)

Pada percakapan pedagang 1 dan pembeli pada data di atas menunjukan dialek sosial penutur dengan penggunaan pilihan kata sapaan [yañ] seperti pada tuturan (3), kata sapaan ini digunakan pedagang untuk menyapa pembeli yang berjenis kelamin perempuan.

Pedagang 1 ini berjenis kelamin perempuan, kalimat yang digunakannya ketika berhadapan dengan pembeli cenderung panjang, megandung basa-basi seperti yang terdapat pada tuturan 3 yaitu [kudai, kito kina? i kudai bəyapo baña? lagi,.....] meskipun tuturan yang diungkapkannya tersebut bukanlah jawaban dari pertanyaan pembeli, karena pembeli bertanya jenis ikan yang dijual si pedagang tersebut. Tuturan yang 
disampaikan oleh pedagang yang berjenis kelamin perempuan cenderung disertai gerakan seperti menimbang ikan, meskipun belum diketahui berapa banyak yang diinginkan oleh pembeli.

\section{Data 70 : PD6/PD1/U153}

Pedagang (6): Ikannya mbak (151)

Pembeli (1): Lelenya om (152)

Pedagang (6): piro mbak e? [piro

mba? e] (berapa mbak?) (153)

Pembeli (1): Setengah kilo aja (154)

Pedagang 6 ini berjenis kelamin lakilaki, ketika berinteraksi dengan pembeli pedagang ini hanya menggunakan kalimat seperlunya saja, tidak banyak basa-basi, ia langsung ke inti atau pokok permasalahan seperti pada tuturan (153) yaitu [piro mba?e], ia langsung menanyakan berapa banyak jumlah ikan yang diinginkan oleh pembeli.

Dilihat dari penggunaan kata sapaan [mba?]yang digunakan pedagang untuk menyapa seorang perempuan yangberpenampilan ataupun raut wajah masih mudaseperti yang terdapat pada tuturan (151) yaitu [ikanña mba?].Berdasarkan informasi yang didapatkan oleh penulis, bahwa pedagang 6 ini bukanlah seorang laki-laki keturunan Jawa melainkan asli keturunan Melayu Bengkulu, akan tetapi karena aktivitas sebagai pedagang sudah cukup lama ia tekuni dan sudah bertemu dengan pelanggan yang menggunakan berbagai macam bahasa, menjadikan ia banyak mengetahui jenis bahasa yang ada terutama bahasa di daerah provinsi Bengkulu dan sekitarnya.

Perempuan dan laki-laki memiliki pola pikir yang berbeda-beda, maka tentu saja cara berkomunikasinya juga berbedabeda, mulai dari pilihan kata hingga kalimat yang digunakan ada yang panjang, dan ada juga yang pendek, kalimat yang diungkapkan oleh pedagang yang berjenis kelamin laki-laki biasanya seperlunya saja, berbeda dengan perempuan yang kalimatnya cenderung panjang dan banyak basa-basi untuk menarik minat pembeli agar tertarik membeli ikan dagangannya.

\section{d. Variasi bahasa berdasarkan usia \\ Data 71 : PD7/PB1/U155}

Pedagang (7): Jangan berebut-berebut, masih ado lele na

[jañan bər ${ }_{\gamma}$ but-bərəbut, masih ado lele na]

(jangan rebutan, masih ada lele) (155)

Pedagang 7 ini adalah seorang pedagang sekaligus pelajar yang masih duduk di bangku SMP, ia bernama Andika yang berusia 15 tahun. Ketika sedang berjualan ikan, pedagang yang masih remaja ini cendrung berjualan dengan mengeluarkan kata-kata dengan suara yang keras dan lantang seperti yang terdapat pada tuturan (155) yaitu [jañan bərəbut-bərəbut, masih ado lele na] sebagai bentuk promosi ataupun mempengaruhi pembeli yang melewati daganganya, karena pada saat itu pengunjung pasar sangat ramai. Sedangkan pedagang yang berusia 40an cenderung menggunakan kata yang secukupnya saja walaupun tujuannya sama yaitu memperkenalkan ikan dagangannya agar menimbulkan ketertaikan pembeli meskipun situasi pasar sangat ramai dengan pembeli.

\section{Fungsi Bahasa}

Dalam penelitian ini penulis
menemukan beberapa fungsi yang
terdapat pada percakapan pedagang dan
pembeli yaitu fungsi personal, regulatori
atau direktif, dan interaksional dan
instrumental.

\section{(a) Fungsi Personal}

Dari kutipan percakapan pada data hasil penelitian terlihat bahwa pedagang 1 mengungkapkan apa yang ada 
dipikirannya kepada pedagang 2 seperti yang terlihat pada tuturan (68) yaitu [maanoo jəmo ənda? bəlanjo ikan kito ne, ikan ituu, ikan ini, ikan itu ikan ini kəlo tu] yang jika diartikan ke dalam bahasa Indonesia menjadi [mana orang yang mau belanja ikan kita ini, ikan itu, ikan ini, ikan itu ikan ini nanti tu]. Melalui tuturan tersebut pedagang 1 mengungkapkan bahwa ia mengharapkan adanya pembeli yang tertarik dan ingin membeli ikan dagangannya dari berbagai jenis ikan yang dijualnya muali dari ikan tuna, dencis, kerong, gelamo, dan tongkol, yang dipertegas dengan kalimat [ikan itu, ikan ini, ikan itu ini kəlo tu]yang menunjukan suatu harapan pedagang 1.

Kemudian dari tuturan

pedagang 1 juga mengungkapkan perasaannya atau menceritakan isi hatinya kepada pedagang 2 sambil mengambil beberapa tumpukan ikan di hadapan pedagang 2 kemudian dipindahkan ke hadapannya, seperti yang terlihat pada tuturan (71) yaitu[Contoño ñambe? ke sini lah jualan, dapat upah nimbañ jadilah a ma?, ca? itu lah gawejualan ni] ujaran ini masih merupakan ungkapan perasaan dari pedagang 1, dari tuturan tersebut terdapat makna tersirat yang disampaikan oleh pedagang 1,yaitu walaupun jualannya tidak ada yang membeli akan tetapi jualan pedagang 2 yang dihadapannya yang dibeli, setidaknya ia mendapatkan upah dari menimbang ikan.

\section{(b) Fungsi Regulatori}

Pada percakapan data hasil penelitian terlihat bahwa pedagang 3 berusaha menyakinkan pembeli seperti yang terlihat pada tuturan (134)[ikanño masih səgar de?], dari tuturan tersebut memiliki makna bahwa ikan kerong yang ditawarkannya masih dalam keadaan bagus dan segar. Melalui tuturan tersebut Pedagang meyakinkan lawan tuturnya agar tertarik untuk membeli ikan kerong tersebut. Dan ternyata setelah berkomunikasi lebih lanjut antara pedagang dan pembeli yang membicarakan seputar ikan kerong tersut, akhirnya pedagang berhasil mempengaruhi dan meyakinkan pembeli pembeli, sehingga ia tertarik untuk membeli ikan terseut meskipun mengajukan syarat kepada pedagang yang menghendaki adanya tindakan atau perlakukan lawan tuturnya.

Dari kutipan percakapan pada data hasil penelitian terlihat bahwa pedagang berusaha meyakinkan pembeli seperti yang terlihat pada tuturan (83) [wei baru itu yañ, itu kurañ gəbus itu de? mañko dio licin tu, kalu dio masa? gəbusño ida? licin dio, baru ituu, pagi tadi lah, pagi tadi lah itu yañ.....], dari tuturan tersebut terlihat bahwa pedagang membela diri dengan meyakinkan pembeli bahwa siput yang dijualnya masih dalam keadaan bagus dan proses perebusan terjadi dipagi harinya sehingga dapat disimpulkan bahwa siput tersebut memang masih bagus, karena kurang matang saat proses perebusan hingga menyebabkan adanya lendir-lendir berwarna putih yang licin pada siput tersebut.

Dengan kemahiran pedagang dalam merayu, meyakinkan dan mempengaruhi lawan tuturnya, maka akan sangat menguntungkan bagi para pedagang, karena bisa memikat lawan tuturnya untuk membeli dagangannya. Namun tidak semua rayuan yang diajukan pedagang itu berhasil memikat hati pembeli, seperti yang terdapat pada pedagang 7 ia mengalami kegagalan dalam memikat hati pembeli.

(c) Fungsi Interaksional 
Dalam komunikasi antara penutur dan pembeli menggunakan kata sapaan yang melihatkan perbedaan usia, dan kata sapaan yang digunakan pedagang merupakan bentuk keramah-tamahan pedagang dalam menjalin hubungan baik antara pedagang dan pembeli, dengan adanya kata sapaan akan membuat pembeli merasa nyaman dan akrab sehingga menimbulkan kesan yang sopan bagi pelanggan dan menimbulkan ketertarikan pembeli untuk membeli ikan dagangannya.

Dari kutipan data di atas terlihat bahwa penutur dan mitra tutur menggunakan kata sapaan [yu?] dan [de?] dalam percakapannya mengenai harga ikan. Penggunaan kata sapaan ini memperlihatkan usia penuturnya seperti pada tuturan (72) pembeli menggunkan kata sapaan [yu?] yang menunjukan bahwa usianya lebih mudah dari pedagang, dan dapat diketahui pula dari penggunaan kata sapaan [yu?] oleh pembeli menunjukan bahwa raut wajah pedagang belum terlalu tua, sehingga masih pantas untuk di sapa dengan kata [yu?].

Fungsi interaksional bukan hanya berfokus pada linguistiknya saja tetapi juga didukung dengan nonverbal penutur seperti gestur, kontak mata, dan ekspresi raut muka. Hal seperti ini dapat dilihat pada tutran (73) [bərapo de? sətəñah, apo ambia? galo? (langsung menimbang), na lapan ons setengah, ambia?Lah] yang menunjukkan gestur pedagang yang langsung menimbang ikan dan menatap sambil mengarahkan timbangan kepada pembeli yang berada dihadapannya, bahwa berat ikan delapan ons setengah.

\section{(d) Fungsi Instrumental}

No. Data 100 : PD8/PB2/U179, 181

Pedagang (8): tukar dulu, ado duit limo puluh duo (bertanya kepada pedagang di sebelah sebelahnya) [tukar dulu, ado duit limo puluh duo] (tukar dulu, ada uang lima puluh ribu dua lembar) (179)

Pedagang (8): na

(langsung

mengambilnnya). Seribunyo tambah ikan ajo yo bunda. [na. səribuño tambah ikan ajo yo bunda]

(na, seribunya tamba ikan saja ya bunda) (181)

Dari kutipan percakapan pedagang 8 di atas terlihat bahwa pedagang tidak memiliki uang pecahan untuk mengembalikan sisa uang yang dibayarkan oleh pembeli, maka sebagai tindakkannya pedagang 8 ingin menukar uang seratus ribu rupiah dengan uang pecahan lima puluh ribu rupiah dengan pedagang yang berada disebelahnya seperti yang terdapat pada tuturan (179) selain itu juga terdapat pada tuturan (181) yang menginginkan uang kembalian seribu rupiah diganti dengan seekor ikan saja, karena pedagang tidak memiliki uang pecahan sebagai kembalian.

Hal ini lah yang dimaksudkan bahwa bahasa berfungsi sebagai alat untuk mendapatkan sesuatu. Ujaran yang diungkapkan oleh pedagang tersebut sebagai alat untuk mendapatkan sesuatu dari lingkungannya, yaitu alat untuk mendapatkan tukaran uang seratus ribu rupiah menjadi dua lembar uang lima puluh ribuh rupiah. Dan sebagai alat untuk memanipulasi lingkungan agar terjadi suatu peristiwa seperti yang terdapat pada tuturan (181) yang menginginkan kembalian yang berjumlah seribu rupiah diganti dengan seekor ikan, dikarenakan pedagang 8 ini tidak memiliki uang pecahan untuk mengembalikan sisa uang yang dibayarkan pembeli.

\section{(e) Fungsi Heuristik}


No. Data 100 : PD8/PB2/U179, 181

Pedagang (8): tukar dulu, ado duit limo puluh duo (bertanya kepada pedagang di sebelah sebelahnya) [tukar dulu, ado duit limo puluh duo] (tukar dulu, ada uang lima puluh ribu dua lembar) (179)

Pedagang (8): na

(langsung

mengambilnnya). Seribunyo tambah ikan ajo yo bunda.

[na. səribuño tambah ikan ajo yo bunda]

(na, seribunya tamba ikan saja ya bunda) (181)

Dari kutipan percakapan pedagang 8 di atas terlihat bahwa pedagang tidak memiliki uang pecahan untuk mengembalikan sisa uang yang dibayarkan oleh pembeli, maka sebagai tindakkannya pedagang 8 ingin menukar uang seratus ribu rupiah dengan uang pecahan lima puluh ribu rupiah dengan pedagang yang berada disebelahnya seperti yang terdapat pada tuturan (179) selain itu juga terdapat pada tuturan (181) yang menginginkan uang kembalian seribu rupiah diganti dengan seekor ikan saja, karena pedagang tidak memiliki uang pecahan sebagai kembalian.

Hal ini lah yang dimaksudkan bahwa bahasa berfungsi untuk memecahkan suatu masalah. Ujaran yang diungkapkan oleh pedagang tersebut untuk memecahkan suatu masalah yang dihadapinya, yaitu untuk mendapatkan tukaran uang seratus ribu rupiah menjadi dua lembar uang lima puluh ribuh rupiah.

\section{Pembahasan}

Kevariasian bahasa terjadi karena interaksi sosial yang beragam, seperti di Pasar Panorama Bengkulu yang memiliki masyarakat bahasa dengan latar belakang yang berbeda-beda. Hal ini menimbulkan variasi bahasa terutama kevariasian bahasa yang dilihat dari segi penutur yang memuat idiolek, dan sosiolek penutur yang meliputi asal daerah, jenis kelamin, dan usiapenuturnya.

Kevariasian bahasa pedagang ikan di pasar Panorama Bengkulu yang dilihat dari segi penutur tampak pada idiolek pedagang yang menggunakan pilihan kata yang, bunda, yang menandakan ciri kekahasannya. Kemudian tampak pada bahasa pedagang dari berbagai asal daerah yang ada di provinsi Bengkulu seperti yang menggunakan bahasa Melayu Bengkulu [yo, ajo, bərapo, ida?, -ño, apo], bahasa Serawai daerah Seluma [bəgapo, kudai, anjua?, nañay, sapulua], bahasa Serawaidaerah Bengkulu Selatan [andia?, ngapaw, pulaw], bahasa Lintang daerah Empat Lawang [bərapa, nədo, adə], bahasa Jawa [piro].

Variasi bahasa berdasarkan jenis kelamin penutur, terdapat pedagang yang berjenis kelamin perempuan dengan penggunaan kalimat yang cenderung panjang, dan mengandung basa-basi, serta pedagang yang berjenis kelamin laki-laki yang menggunakan kata atau kalimat secukup dan seperlunya saja. Variasi bahasa berdasarkan usia penuturnya juga membedakan setiap usia seperti remaja dan dewasa, perbedaannya terletak pada pilihan kata, jika pedagang usia remaja menggunakan kalimat yang panjang diucapkan dengan nada suara yang keras dan lantang, berbeda dengan pedagang yang berusia dewasa yang hanya menyapa pembelinya dengan kata sederhana seperti "ikannya mbak" yang diucapkan dengan nada pelan.

(3)fungsi interaksionalmerupakan fungsi bahasa yang menjalin hubungan sosial. Dalam percakapan antara pedagang ikan dan pembeli di pasar Panorama Bengkulu menggunakan kata sapaan sebagai bentuk keramatamahan dan kesopanan pedagang dalam menjalin hubungan baik dengan pembeli seperti kata sapaan [de?, yañ, yu?, pa?, mba?, 


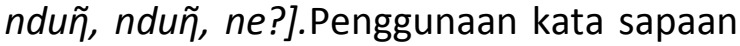
sangat diperlukan dalam berkomunikasi dengan orang lain, dengan adanya kata sapaan yang digunakan penutur dan lawan munculah rasa saling menghargai, sehingga menimbulkan kenyamanan dan keakraban diantara keduanya.

(4) fungsi instrumental merupakan fungsi bahasa sebagai alat untuk mendapatkan sesuatu dari lingkungannya, seperti dalam penelitan ini pedagang menggunakan bahasa untuk mendapatkan sesuatu dari lingkungannya yaitu menukar uang pecahan dengan teman sesama pedagang ikan disebalahnya, seperti pada ujaran [tukar dulu, ado duit limo puluh].

(5) fungsi heuristik merupakan fungsi bahasa untuk memecahkan masalah yang tengah dihadapi penutur dan lawan tutur. Dalam penelitian ini fungsi heuristik terlihat bahwa pedagang mengalami kendala dalam mengembalikan uang pembeli dikarenakan ia tidak memiliki uang pecahan seribu rupiah, sebagai tindakannya untuk memecahkan masalah seperti pada tuturan (saribuño tambah ikan ajo yo bunda], dari tuturan tersebut pedagang menyarankan agar uang kembalian seribu rupiah diganti atau ditambah dengan ikan saja.

Dalam fungsi ini, fungsi bahasa tidak hanya terlihat pada aspek bahasa atau verbal yang digunakan saja,tetapi juga terdapat pada aspek nonverbal yang mendukung aspek verbalnya, seperti gestur atau gerak tubuh, kontak mata, ekspresi muka dapat berupa senyuman, dan lain-lain.

Bahasa dan masyarakat hidup bersamaan, keduanya tumbuh kembang secara bersamaan pula, bahasa bisa bertahan dan berkembang karena adanya masyarakat sebagai penutur, begitu juga sebaliknya bahwa masyarakat berkembang dan maju dengan segala ilmu pengetahuan yang dimiliki karena adanya bahasa. Itu sebabnya mengapa bahasa dan manusia tidak dapat dipisahkan

\section{PENUTUP}

\section{Kesimpulan}

Berdasarkan pemaparan hasil penelitian, maka dapat disimpulkan bahwa:

1. Variasi bahasa pedagang ikan di pasar Panorama Bengkulu dari segi penutur terdapat :

a) Idolek pedagang yang menggunakan pilihan kata sapaan [yang] dan kata sapaan [bunda] yang menjadi ciri khas penutur ketika berinteraksi dengan pembeli sebagai lawan tuturnya.

b) Terdapat beberapa bahasa yang menunjukkan asal daerah penuturnya diantaranya bahasa Melayu Bengkulu [yo, ajo, barapo, ida?, -ño, apo], bahasa Serawai daerah Seluma [bagapo, kudai, anjua?, nañay, sapulua], bahasa Serawai daerah Bengkulu Selatan

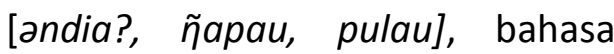
Lintang daerah Empat Lawang [brrape, nedo, ade], bahasa Jawa [piro] penggunaan bahasa daerah ini dipengaruhi latar belakang penutur maupun tempat dan situasi tuturan berlangsung.

c) Terdapat variasi bahasa yang menunjukan jenis kelamin dan usia seperti pedagang yang berjenis kelamin perempuan dengan kalimat yang panjang dan mengandung basa-basi, sedangkan pedagang berjenis kelamin laki-laki cenderung pendek dan seperlunya saja.

2. Fungsi bahasa pedagang ikan di pasar Panorama Bengkulu mengandung beberapa fungsi yaitu personal untuk mengungkapkan perasaan penuturnya, fungsi regulatori untuk mempengaruhi atau membujuk pembeli agar tertarik 
membeli ikan dagangannya, dan interaksional untuk menjalin hubungan sosial anatara pedagang dan pembeli, dan instrumental untuk mendapatkan sesuatu dari lingkuannya serta fungsi heuristik untuk memecahkan masalah yang dihadapi penutur dan lawan tutur ketika sedang berinteraksi.

\section{DAFTAR PUSTAKA}

Alwasilah, C. 1985. Sosiologi Bahasa. Bandung: ANGKASA.

Aslinda, \& Syafyahya, L. 2007. Pengantar Sosiolinguistik. Bandung: Refika Aditama.
Chaer, A., \& Agustina, L. 2010. Sisiolinguistik Perkenalan Awal. Jakarta: penerbit Rineka Cipta.

Nababan. 1984. Sosiolinguistik Suatu Pengantar. Jakarta: PT Gramedia.

Padmadewi, N. N., Merlyna, P. D., \& Saputra, N. P. 2014. Sosiolinguistik. Yogyakarta: Graha Ilmu.

Rokhman, F. 2013). Sosiolinguistik. Yogyakarta: Graha IImu.

Sugiyono. 2014. Metode Penelitian Kuantitatif Kualitatif dan $R \& D$. Bandung: ALFABETA. 